\title{
Impact of Digital Marketing on Consumer Purchase Decision
}

\author{
K.Ravindran, V.Sathyamoorthi
}

\begin{abstract}
-promoting is a trifling exchange of goods and services for cost but advertising and marketing is the phenomenon that allows keeping clients other than attracting them. Within the gift era among the numerous modes of marketing, digital marketing occurs to generate the maximum fee. It could be as the mechanism of reaching consumers through the use of diverse virtual distribution channels. The present observes aims to observe the effect of digital marketing and advertising on client purchase conduct and additionally makes an attempt to investigate as to in what ways are the clients absolutely privy to the diverse digital marketing and advertising mediums inside the gift digital generation. The look at is primarily based on the survey method. A questionnaire is prepared and covered 786 respondents for evaluation. The effects of the look at discovered the information that the purchasers are privy to the digital mediums available to them. It also confirmed the results that most of the customers opt to shop online due to its ease of use and in your price range mode of buying. Because of the technological upliftment in the gift generation, digital mediums and digital marketing are gaining significance and is enormously prevalent via each stratum of the society.
\end{abstract}

Keywords: Digital marketing, buy behavior, clients Medium

\section{INTRODUCTION}

The terms marketing and selling are used interchangeably but there is a wide difference between the two. Selling is mere exchange of goods and services for cash or in simple terms conversion of products into cash. But marketing includes selling and also is concerned with all the activities that are associated with all the activities that are associated with meeting and satisfying customers' needs. Being a variant of advertising and marketing digital marketing encompasses all advertising efforts that use an electronic device or medium to reach the customers and meet their requirements. Invent of digital marketing since 1900 s and 2000s has changed the manner manufacturers and agencies use era for advertising and marketing.

Digital advertising and marketing techniques together with search engine optimization (search engine optimization), content material advertising and marketing, seek Engine advertising and marketing (SEM) affect marketing, and content material automation marketing campaign marketing, e-trade advertising, social media optimization, ebooks.

Revised Manuscript Received on December 09, 2019

Dr.K.Ravindran, (Correspondence Author) Department of Business Administration, Kalasalingam Academy of Research and Education, Krishnankoil-626126, Virudhunagar, Tamilnadu, India. Kravindranmba5@gmail.com

Mr.V.Sathyamoorthi, Department of Business Administration, Kalasalingam Academy of Research and Education, Krishnankoil-626126, Virudhunagar, Tamilnadu, India. sathyamba7@gmail.com

And optical disks have become more and more outstanding with the advancing technology. In truth, digital marketing has succeeded to attain out the clients through non-net channels that provide digital media which include mobile phones (SMS \& MMS) callback and on keep mobile ringtones.

The marketing of products through internet as a medium also allows the business to be in a constant touch with the customers 24/7 which additionally makes the customers feel valued and supported. At the same time it is possible for the business to keep a track of their business and its performance through constant feedback system from the customers.

Digital advertising and digital marketing are comparable phrases which honestly consult with "advertising on line whether or not via web sites, online advertisements, opts in emails, interactive kiosks, interactive TV or mobiles (Chaffey and Smith 2008). And as a consequence social media advertising one of the maximum vital components of digital marketing ensures reaching the target audience easily without paying any extra expenditure to publishers or distributors unlike traditional marketing. It is increasingly popular with various class of business to reach the customers through social media platforms. The capacity-reach of social media is indicated through the reality that in 2015 , each month the Face book app had greater than 126 million common specific customers and You tube had over ninety-seven million common precise customers.

The objective of the study is to

1. To assess the extent of awareness about digital marketing and advertising the various clients.

2. To have a look at the impact of digital marketing on consumer buy selection.

3. To know the elegance of products purchased with the aid of using digital channels.

4. To have a look at the most utilized method of digital marketing.

\section{LITERATURE REVIEW}

With the invent and acceptance of telephone, of internet over all these electronic media or medium digital marketing has started occupying a dominant position in the market. Khan and Mahapatra (2009) mentioned that 
technology plays an essential role in enhancing the pleasant of offerings as provided through commercial enterprise corporations. As also remarked with the aid of (Ganeshwar 2013) digital advertising and marketing lets in the customers to be in constant contact with the precise updates and information released by using the organization

One to the technical know-how within very literate it smooth for them to get admission to the business enterprise internet site, observe the updates make online purchases and offer remarks. Clients obtain complete data related to the goods and or offerings (Gregory Karp, 2014).

Elisabeta Loanals (2014) tested the impact of digital advertising and marketing on consumers buy selection thru a survey of 116 respondents. His consequences declared that digital marketing has a profound effect on variations of purchasing selection. Sadia Afzal (2015) cited in his paper the difference in the impact of an everyday advertisement and digital advertisement on clients purchase selection of garb. Virtual advertisement covers various aspects which the ordinary ones leave out to do the identical. This in flip leaves a big impact on the acquisition decision.

Basheer (2010) came up with the conclusion that there's an effective connection among digital markrting and purchase selection by means of inspecting the impact of SMS commercial on consumer state of mind and his intentions. Tia and Manish (2012) stated that most of the buyers in metropolitan India are sorting e commerce for their purchase selection.

Kee (2008), Godes and Silva(2012) have remarked the important analysis that most of the customers read the reviews of other online customers before making their purchase decision. Consumers at least read 4 reviews before finalizing their purchase decisions Evaluations play a critical function in the purchase choice.

Based on the reviews made and discussed above it is clear that there is a change in pattern and trend of the Customers buy encountered due to the emergence of digital marketing and advertising. As a result of the take a look at makes a specialty of assessing the level of awareness approximately digital marketing among the customers and its effect on their purchase decision.

\section{METHODOLOGY}

Each number one and secondary statistics used for the examine. Number one statistics were accrued through the questionnaire. Secondary data became taken from posted resources like journals, internet, books, and articles; evaluation has been made on the idea of reaction received from the respondents. The research type involves Descriptive. 783 customers were selected at $95 \%$ confidence level and $0.035 \%$ of margin of error. The data have been collected by using the structured questionnaire with a probability resign of simple random sampling.

\section{RESULTS}

The respondents were asked to explicit their opinion on a 5-factor Likert scale. The scores had been assigned as strongly agree (five factors) to strongly disagree (1 point). The preliminary evaluation changed into made using descriptive evaluation.

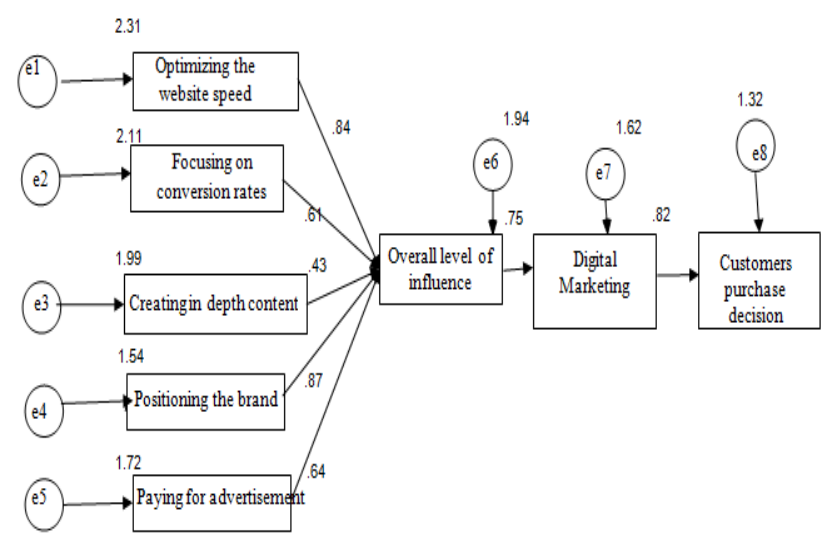

\section{Figure 1: Structural model - standardized regression weight Factor loadings}

This assessment estimates the standardized loadings of the various latent variables and observed variables as indicators of the constructs. This SEM diagram shows the relationships between all the endogenous and exogenous constructs are highly significant.

Table 1: Structural model - Covariance relationship estimate

\begin{tabular}{|c|c|c|c|c|c|}
\hline \multicolumn{3}{|c|}{ Covariance relationship estimate } & \multirow{2}{*}{$\begin{array}{r}\begin{array}{c}\text { Beta } \\
\text { estimate }\end{array} \\
.840\end{array}$} & \multirow{2}{*}{$\begin{array}{l}\text { C.R. } \\
9.558\end{array}$} & \multirow{2}{*}{$\begin{array}{c}\mathrm{P} \\
* * *\end{array}$} \\
\hline $\begin{array}{l}\text { Optimizing } \\
\text { the website } \\
\text { speed }\end{array}$ & $--->$ & $\begin{array}{l}\text { Digital } \\
\text { marketing }\end{array}$ & & & \\
\hline $\begin{array}{l}\text { Focusing on } \\
\text { conversion } \\
\text { rates }\end{array}$ & $--->$ & $\begin{array}{l}\text { Digital } \\
\text { marketing }\end{array}$ & 1.609 & 13.404 & $* * *$ \\
\hline $\begin{array}{l}\text { Creating in } \\
\text { depth content }\end{array}$ & $--->$ & $\begin{array}{l}\text { Digital } \\
\text { marketing }\end{array}$ & .434 & 4.595 & .042 \\
\hline $\begin{array}{l}\text { Positioning } \\
\text { the brand }\end{array}$ & $--->$ & $\begin{array}{l}\text { Digital } \\
\text { marketing }\end{array}$ & .375 & 6.728 & $* * *$ \\
\hline $\begin{array}{l}\text { Paying for } \\
\text { advertisement }\end{array}$ & $--->$ & $\begin{array}{l}\text { Digital } \\
\text { marketing }\end{array}$ & .346 & 6.268 & .038 \\
\hline $\begin{array}{l}\text { Digital } \\
\text { marketing }\end{array}$ & $--->$ & $\begin{array}{l}\text { Customers } \\
\text { purchase } \\
\text { decision }\end{array}$ & .424 & 5.475 & .035 \\
\hline
\end{tabular}

Structural diagram of the analysis presented in Figure 1, depicts the standardized model based on the five latent variables, Optimizing the website speed, Focusing on conversion rates, Creating in depth content,

Published By: 
Positioning the brand and Paying for advertisement shows the relationship between the factors affecting digital marketing and digital marketing. Table 1 represents the results of the Covariance relationship estimate among the latent variables, dependent variable and mediating variable. The critical value, which is more than 1.96 , is considered to be significant (David Garson, 2016).

The critical value of latent variables, Optimizing the website speed (9.558), Focusing on conversion rates (13.404), Creating in depth content (4.595), Positioning the brand (6728) and Paying for advertisement (6.268) have a positive impact with digital marketing. Digital marketing (5.475) have a positive impact with Customers purchase decision.

\section{DISCUSSION}

Digital marketing due to the onset of various advantages associated with it has become the best platform to convert a product into brand. The first and foremost advantage is cost efficiency. Digital marketing being economical for both producers and consumers has become the preferred choice for both the segments of the market. Digital media not only attract new customers but also retain the existing ones as well. The present study clearly portrays how digital marketing attracts and influences the customers in their purchase decision irrespective of their income or geographical location.

\section{SUGGESTIONS}

* Digital marketing needs to create more awareness in the minds of the customers for its better further usage

* Customer desires must be the peak priorities for digital marketing

* The digital platforms must at the end the customers properly during and after purchase

* Complete and relevant data about the product should be provided in case of online purchases.

\section{REFERENCES}

1. G. Eason, B. Noble, and that i. N. Sneddon, "On certain integrals of Lipschitz-Hankel type regarding merchandise of Bessel capabilities," Phil. Trans. Roy. Soc. London, vol. A247, pp. 529-551, April 1955. (references)J. Clerk Maxwell, A Treatise on Electricity and Magnetism, 3rd ed., vol. 2. Oxford: Clarendon, 1892, pp.68-73.

2. I. S. Jacobs and C. P. Bean, "Fine particles, thin films and exchange anisotropy," in Magnetism, vol. III, G. T. Rado and H. Suhl, Eds. New York: Academic, 1963, pp. 271-350.

3. K. Elissa, "Title of paper if known," unpublished.

4. Chaffey D \& Smith P, E-Marketing Excellence: Planning and Optimizing Your Digital Marketing, Routledge. Fourth Edition, 2008, 580-593

5. Waghmare GT, E-Commerce, A Business Review and Future Prospects in Indian Business. Internet, Marketing in India. Indian Streams Research Journal, 2(5), 2012.

6. international journal of business management

7. Sadia Afzal,Javed Rabbani Khan. (2015). "Impact of online and conventional advertisement on consumer buying behaviour of branded garments". Asian Journal of Management Sciences \& Education, 4.
8. Godes, D., \& Silva, J. C. (2012). "Sequential and temporal dynamics of online opinion". Marketing Science, 31(3), 448-473.

9. Kee, R. (2008). "The sufficiency of product and variable costs for production-related decisions when economies of scope are present" . International Journal of Production Economics, 114(2), 682-696.

\section{AUTHORS PROFILE}

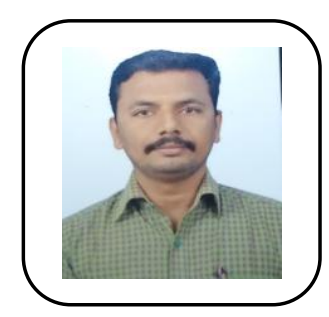

Dr.K.Ravindran MBA., MSW., M,Phil. Ph.D. He has published more than five articles in the UGC listed journals and Scopus indexed journals. He has acting as Guide for Ph.D Programme in Kalasalingam Academy of Research and Education, Virudhunagar District. He has received best teacher award. $\mathrm{He}$ has presented more than fifteen papers in the National and International level seminars and conferences organized by Various colleges and universities in India.

Mr.V.SathyamoorthyMBA., He has persuing $\mathrm{Ph.D}$ at Kalasalingam Academy of Research and Education, Virudhunagar District. He has presented more than five papers in the national and international level seminars and conferences. 